\title{
Anal Cancer cM1 TNM Finding v7
}

National Cancer Institute

\section{Source}

National Cancer Institute. Anal Cancer CM1 TNM Finding V7. NCI Thesaurus. Code C90030.

Anal cancer with distant metastasis. (from AJCC 7th Ed.) 